CASE REPORT

\title{
Hypopharyngeal perforation following minor trauma: a case report and literature review
}

\author{
D Smith, S Woolley
}

Emerg Med J 2006;23:e7 (http://www.emjonline.com/cgi/content/full/23/1/e7). doi: 10.1136/emj.2003.012187

Hypopharyngeal perforation is mainly reported in association with high velocity road traffic accidents, or with low velocity direct blows to the neck. We report a case of hypopharyngeal perforation following a low velocity motorcycle accident where neither of these mechanisms of injury was apparent. A 52 year old man was referred from the emergency department (ED) with a sore throat and dysphagia, following a low speed side impact accident. A gastrograffin swallow demonstrated a posterior pharyngeal wall tear. After 11 days of conservative hospital treatment, he recovered and was discharged. The presumed mechanism of injury in this case was cervical spine hyperextension without cervical compression.

$\mathrm{H}$ ypopharyngeal perforation, a rare complication of nonpenetrating blunt neck trauma, is mainly reported in association with high velocity road traffic accidents. ${ }^{1-7}$ The proposed mechanism of injury is neck hyperextension associated with airway closure due to cervical compression against the steering wheel. Low velocity direct blows ${ }^{148-10}$ to the neck have also been associated with pharyngeal perforation. We report a case of hypopharyngeal perforation following a low velocity motorcycle accident where neither of these mechanisms of injury was apparent. The presumed mechanism of injury in this case was cervical spine hyperextension without cervical compression.

\section{CASE REPORT}

A 52 year old man was referred from the emergency department (ED) with a sore throat and dysphagia. He had fallen from his motorcycle, following a low speed side impact accident. He was ambulant at the scene, complaining only of a painful ankle and a sore throat. His motorcycle helmet was undamaged.

Physical examination in the ED was normal. In particular, there was no evidence of head or cervical spine injury, no evidence of external neck trauma, and no subcutaneous emphysema. He complained of a persistent sore throat but did not have a hoarse voice. Lateral cervical spine radiographs demonstrated retropharyngeal free air. Flexible nasoendoscopy was normal. A gastrograffin swallow demonstrated a posterior pharyngeal wall tear. He was admitted under the care of the otolaryngologists, kept "nil by mouth", and given intravenous cefuroxime, metronidazole, and fluids. A gastrograffin swallow on day 4 demonstrated a persistent pharyngeal tear. Nasogastric feeds were commenced and intravenous antibiotics continued for a further week. Following radiological confirmation of a healed tear, the patient was discharged on day 11 .

\section{DISCUSSION}

Oesophageal perforation following external blunt trauma is rare. A review in $1962^{11}$ identified only 30 reported cases over a 62 year period. Pharyngeal perforations are even rarer, accounting for $<2 \%$ of all perforations in the pharyngoesophageal region. ${ }^{12}$ Recognised causes of pharyngeal perforation include iatrogenic causes, blunt and penetrating trauma, spontaneous perforation, ${ }^{13}$ swallowed foreign bodies, ${ }^{15}$ blast injury, and emesis. ${ }^{14}$

The commonest cause of pharyngeal perforation is iatrogenic, usually secondary to instrumentation. Hypopharyngeal perforation secondary to endotracheal intubation is more likely to occur with difficult intubations, ${ }^{15}$ in the pre-hospital setting, ${ }^{16}$ or when performed by inexperienced anaesthetists. ${ }^{17-19}$ Neonatal perforations are associated with rigid suction catheter use, ${ }^{20}$ nasogastric ${ }^{21}$ and endotracheal tube placement, ${ }^{22}$ and digital trauma during resuscitation. ${ }^{23}$ Diagnostic/therapeutic endoscopy has a perforation incidence of between $0.01 \%$ (flexible) and $1 \%$ (rigid). ${ }^{15}$

Blunt trauma occurs with acceleration/deceleration injuries, direct blows to the neck and strangulation. Perforation occurs when laryngeal cartilage is compressed against the vertebral bodies. An anatomical weakness at the hypopharyngeal-oesophageal junction (Killian's dehiscence) predisposes this area to perforation. During compression, the upper airway closes at the level of the hyoid bone. Concurrently, the thorax empties of expired air. If the force of expiration against the closed airway exceeds the "bursting pressure" of the hypopharyngeal-oesophageal junction, perforation occurs with compressed air being forced through the perforation into the cervical soft tissue. Most post-traumatic pharyngoesophageal perforations occur at this level. ${ }^{124}{ }^{25}$ The presence of hypertrophic anterior cervical vertebral osteophytes increases the risk of perforation. ${ }^{26}$

\section{Presentation}

Signs and symptoms of acute pharyngoesophageal perforation include subcutaneous emphysema (extending proximally or distally), chest or neck pain, odynophagia, dysphagia, hoarseness, and haemoptysis. Later presentation with sore throat, dysphagia, swelling, and pyrexia suggests the presence of a retropharyngeal abscess and the associated risk of carotid artery pseudoaneurysm formation, ${ }^{27}$ mediastinitis, pyopneumothorax, septic shock, and death. ${ }^{28}$

\section{Diagnosis}

This is often difficult, and a high index of suspicion is necessary to prevent mortality and morbidity. Unfortunately, the best diagnostic approach is unclear. Plain radiography, laryngoscopy, contrast studies, and computed tomography scans have all been used alone or in combination to confirm clinical suspicion.

The retropharyngeal space (extending from base of the skull to T2-T6) contains fatty tissue and lymph nodes and is, therefore, not usually visible on plain cervical spine radiographs. If air is present, the retropharyngeal space becomes visible in front of the prevertebral soft tissue. Visible retropharyngeal $^{13}$ air on a lateral cervical spine radiograph 
should arouse suspicion of pharyngeal rupture. The differential diagnosis includes retropharyngeal abscess (usually associated with soft tissue swelling), dislocation of the atlanto-occipital joint, and any other cause of pneumomediastinum. Additionally, mediastinal, pericardial, or subcutaneous emphysema ${ }^{129} 30$ on a plain chest radiograph, in the presence of the symptoms described above, should also arouse suspicion of pharyngeal rupture. In some instances, the presence of air, in association with a good clinical history, is sufficient to make a definitive diagnosis. ${ }^{4}{ }^{31}$

Pharyngeal examination is difficult in the presence of free blood. Fibreoptic examination is the diagnostic investigation of choice for obtaining information about the presence, site, and extent of a pharyngeal tear. Additionally, pharyngeal oedema and haematomas may be visualised. ${ }^{1-431}$ Rigid endoscopy gives a superior view but requires a general anaesthetic and is impractical in a patient with an immobilised cervical spine.

Contrast studies may demonstrate the site and extent of any rupture, through extravasation of contrast media. ${ }^{29} 30$ They are $90 \%$ sensitive in oesophageal perforations, ${ }^{29}{ }^{32}{ }^{33}$ but only $60-75 \%$ sensitive in pharyngeal perforations, despite $100 \%$ specificity. ${ }^{29}{ }^{30}$ Lateral or supine decubitus positioning and using barium, rather than water soluble contrast, increases the sensitivity. ${ }^{29} 3034$

Adjunctive use of contrasted CT scans may assist the surgeon preoperatively by demonstrating the exact position and extent of the injury, as well as detecting any other posttraumatic complications including haematomas and laryngeal injury. ${ }^{35}$ This investigation may be preferable in ill patients, as no specific positioning is required. ${ }^{36}$

\section{Management}

Although the morbidity and mortality of untreated perforations is high, optimum management has been controversial, due to their rarity. Early diagnosis and treatment is essential in order to avoid the most frequent complications: mediastinitis, fistulas, and abscesses. ${ }^{1329}$ Traditionally, surgical closure of the perforation was the preferred approach, but over the last 40 years, a number of case series have advocated conservative medical management. ${ }^{17}$ 37-39

A literature review ${ }^{9}$ in 1990 suggested that pharyngeal lesions $<2 \mathrm{~cm}$ should have conservative medical management ${ }^{37}{ }^{38}$ consisting of keeping the patient nil by mouth, the insertion of a nasogastric tube, the administration of intravenous antibiotics and fluids, and total parenteral nutrition where necessary. Oesophageal lesions or pharyngeal lesions $>2 \mathrm{~cm}$ should be managed surgically: drainage ${ }^{124}$ alone or primary surgical closure involving surgical exploration, debridement where necessary, and closure of the perforation. $^{124041}$

\section{CONCLUSION}

Hypopharyngeal rupture following blunt external trauma remains rare. A high index of suspicion is required to prevent morbidity and mortality. Any patient suspected to have a hypopharyngeal perforation (patients with trauma and associated sore throat or dysphagia) should have plain lateral cervical spine and chest radiographs, and a flexible nasendoscopy. Contrast studies and CT scans should be reserved for patients in whom the diagnosis is suspected but unconfirmed by initial investigations. Medical management is appropriate for small lesions limited to the pharynx. Surgical repair and drainage is appropriate for larger perforations and perforations involving the oesophagus.

\section{Authors' affiliations \\ D Smith, University Hospital of Wales, Cardiff, UK}

S Woolley, Bristol Royal Infirmary and Bristol Royal Childrens Hospital, Bristol, UK

Competing interests: there are no competing interests

Correspondence to: Dr S Woolley, A\&E Department, Bristol Royal Infirmary, Bristol BS2 8HW, UK; sarah.woolley@ubht.swest.nhs.uk

Received 28 October 2003

In revised form 12 April 2004

Accepted 10 May 2004

\section{REFERENCES}

1 Hagan WE. Pharyngoesophageal perforations after blunt trauma to the neck. Otolaryngol Head Neck Surg 1983;91:620-6.

2 Yates DW. Steering wheel injury to the pharyngoesophagus. J Trauma 1978;18:77.

3 Gulbrandson RN, Gaspard DJ. Steering wheel rupture of the pharyngoesophagus: a solitary injury. J Trauma 1977;17:74-6.

4 Dolgin SR, Kumar NR, Wykoff TW, et al. Conservative medical management of traumatic pharyngoesophageal perforations. Ann Otol Rhinol Laryngol 1992;101:209-15.

5 Catala J, Puig J, et al. Perforation of the pharynx caused by blunt external neck trauma. Eur Radiol 1998;8:137-140.

6 Jacobs I, Niknejad G, et al. Hypopharyngeal perforation after blunt neck trauma: case report and review of the literature. J Trauma Inj Infect Crit Care 1999;46:957-8.

7 Hagr A, Kamal D, Tabah R. Pharyngeal perforation caused by blunt trauma to the neck. Can J Surg 2003;46:57-8.

8 Wind J. Ruptur des pharynx nach stumpfem halstrauma (A rupture of the dorsal pharyngeal wall following blunt neck trauma: 4th case in the world literature). Laryngol Rhinol Otol (Stutt) 1978;57:573-5.

9 Niezgoda JA, et al. Pharyngoesophageal perforation after blunt neck trauma. Ann Thorac Surg 1990;50:615-17.

10 Back GW, Banfield G. Surgical emphysema and pneumomediastinum in a child following minor blunt injury to the neck. Postgrad Med J 1999;75:548-50.

11 Worman LW, Hurley JD. Rupture of the esophagus from external blunt trauma. Arch Surg 1962;85:173-8.

12 Berry BE, Ochsner JL. Perforation of the esophagus: a 30 year review. J Thorac Cardiovasc Surg 1973;65:1-7.

13 Davidson JJ. Spontaneous rupture of the pharynx. Thorax 1964;19:332-4.

14 Graeber GM, Niezgoda JA, et al. A comparison of patients with endoscopic perforations and patients with Boerhaave's syndrome. Chest 1987;92:995-8.

15 Lee T, Jordan J. Pyriform sinus perforation secondary to traumatic intubation in a difficult airway patient. J Clin Anesth 1996;6:152-5.

16 Wolff A, Kuhn F, Ogura H. Pharyngeal-esophageal perforations associated with rapid oral endotracheal intubation. Ann Otol Rhinol Laryngol 1972;81:258-61

17 Pillay SP, et al. Oesophageal ruptures and perforations-a review. Med J Aust 1989;150:246-52.

18 O'Neill JE, et al. Pharyngeal and esophageal perforation following endotracheal intubation. Anaesthesiology 1984;60:487-8.

19 Levine PA. Hypopharyngeal perforation. An untoward complication of endotracheal intubation. Arch Otolaryngol 1980;106:578-80.

20 Lee SL, Kuhn JP. Esophageal perforation in the neonate: a review of the literature. Am J Dis Child 1976;130:325-9.

21 Kassner EG, Baumstark A, Balsam D, et al. Passage of feeding catheters into the pleural space: a radiographic sign of trauma to the pharynx and oesophagus in the newborn. Am J Roenterol 1977;128:19-22.

22 Astley R, Roberts KD. Intubation perforation of the oesophagus in the newborn baby. Br J Radiol 1970;43:219-22.

23 Meyers AD, et al. Hypopharyngeal perforations in neonates. Arch Otolaryngol 1978;104:51-4.

24 Tucker HM, Padula RT. Non-penetrating traumatic perforation of the pharynx. Arch Otolaryngol Head Neck Surg 1968;68:115-17.

25 Lerscholarn L, Banchuin TD. Cervical esophageal perforation from blunt external trauma. South Med J 1981;74:254-5.

26 Pollock RA, et al. Esophageal and hypopharyngeal injuries in patients with cervical spine trauma. Ann Otol Rhinol Laryngol 1981;90:33-7.

27 Ooi G, Irwin M, Lam L, et al. An unusual complication of emergency tracheal intubation. Anaesthesia 1997;52:154-8.

28 Wengen D. Piriform fossa perforation during attempted tracheal intubation. Anaesthesia 1987;42:519-21.

29 Ghahremani GG. Radiologic evaluation of suspected gastrointestinal perforations. Radiol Clin North Am 1993;31:1219-34.

30 Pasricha PJ, Fleischer DE, Kalloo AN. Endoscopic perforations of the upper digestive tract: a review of their pathogenesis, prevention and management Gastroenterology 1994;106:787-802.

31 Hirsch M, Abramowitz H, Shapira S, et al. Hypopharyngeal injury as a result of attempted endotracheal intubation. Radiology 1978; 128:37-9.

32 Han SY, McElvin RB, Aldrete JS. Perforation of the esophagus: correlation of site and cause with plain film findings. Am J Roentgenol 1983;145:537-40.

33 Parkin GJS. The radiology of the perforated esophagus. Clin Radiol 1973;24:324-32.

34 Dodds WJ, Stewart ET, Vylmen WJ. Appropriate contrast material media for evaluation of eosophageal disruption. Radiology 1982;144:439-41. 
35 Ooms HWA Coerkamp EG. Esophageal perforation: role of esophagography and CT. Am J Roentgenol 1994;162:1001.

36 Endicott JN, et al. Esophageal perforations: the role of computerized tomography in diagnosis and management decisions. Laryngoscope 1986:96:751-7.

37 Mengoli LR, Klassen KP. Conservative management of esophageal perforation. Arch Surg 1965;91:1-7.
38 Cameron JL, et al. Selective non-operative management of contained intrathoracic esophageal disruptions. Ann Thoracic Surg 1979;27:404-8. 39 Keszler P, Buzna E. Surgical and conservative management of esophageal perforation. Chest 1981;80:158-62.

40 Goldstein LA, Thompson WR. Esophageal perforation: a 15 year experience. Am J Surg 1982;143:495-503.

41 Rosoff L, White EJ. Perforation of the esophagus. Am J Surg 1974;128:207-18. 